\title{
Preliminary study on a 3D field permanent magnet flux switching machine - from tubular to rotary configurations
}

\author{
C.F. Wang* and J.X. Shen**
}

\begin{abstract}
A permanent magnet flux switching (PMFS) machine has a simple rotor, whilst both magnets and coils are set in the stator, resulting in easy removal of heat due to both copper loss and eddy current loss in magnets. However, the volume of magnets used in PMFS machines is usually larger than in conventional PM machines, and leakage flux does exist at the non-airgap side. To make full use of the magnets and gain higher power density, a novel 3-dimensional (3D) field PMFS machine is developed. It combines merits of the tubular linear machine, external-rotor rotary machine and axial-flux rotary machine, hence, offers high power density and peak torque capability, as well as efficient utility of magnets owing to the unique configuration of triple airgap fields.
\end{abstract}

Keywords: Permanent magnet, Flux switching, Complex field, Finite element method

\section{Introduction}

A novel 3-dimensional (3D) field 3-phase permanent magnet flux switching machine, which combines the merits of tubular linear machine, external-rotor rotary machine and axial-flux rotary machine, is presented in this paper. It offers high power density and peak torque capability, as well as efficient use of magnets owing to the unique structure of triple airgap fields. Therefore, it can meet the rigorous demands in industry applications.

A rotary permanent magnet flux-switching (PMFS) machine has a simple and robust rotor, which is the same as that of a switched reluctance motor. Furthermore, both magnets and coils are set in the stator. This structure makes it rather easy to take away the heat due to both copper loss and eddy current loss in magnets, compared to conventional PM machines in which either magnets or coils are on the rotor. Considering high power density and peak torque capability, the PMFS machine is suitable for a wide range of applications.

However, the volume of magnets used in the PMFS machine is larger than in the conventional PM machines, whilst leakage flux does exist at the non-airgap side. To make full use of the magnets and gain higher power density, a 3D field 3-phase PMFS machine shown in Fig.1

Hangzhou Municipal Electric Power Bureau, China. (wangcanfei@gmail.com)

** Dept. of Electrical Engineering, Zhejiang University, China. (j_x_shen@zju.edu.cn)

Received 13 October 2012 ; Accepted 10 November 2012 is proposed.

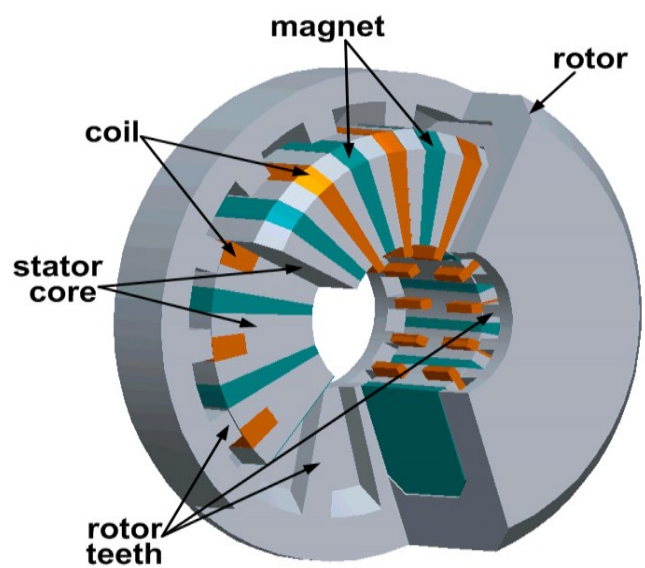

Fig. 1. Schematic of 3D field flux switching machine.

\section{Principle of operation}

The concept of PMFS machine was first proposed in 1955 [1]. In a PMFS motor, the PM-excited flux always exists and has a constant direction in the magnets, as indicated in Fig. 2. However, the flux path changes with the rotor position, resulting in variation of both amount and direction of flux-linkage in the stator coils, and thus inducing back electromotive force (back-EMF) [2].

When currents with appropriate amplitude and phase angles are fed into the coils, the rotor is driven by electromagnetic torque. 


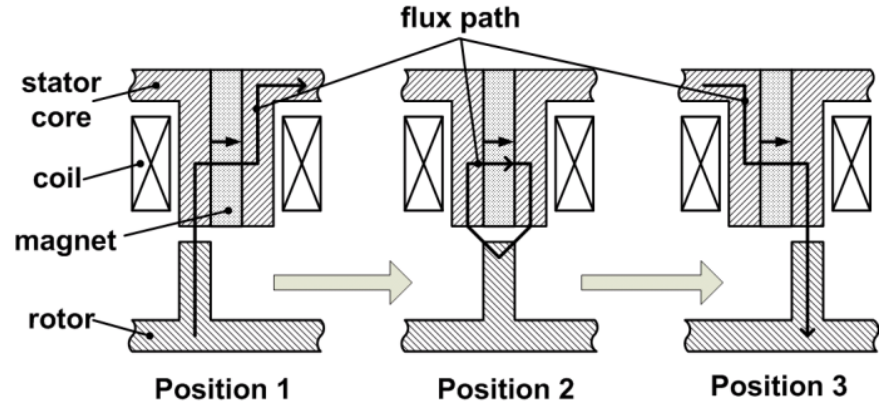

Fig. 2. Principle of flux switching.

\section{Configuration of 3D field PMFS machine}

In the proposed 3D field PMFS machine shown in Fig. 1, the tangentially magnetized magnets with alternate polarities are sandwiched between slotted stator cores, which accommodate the three-phase windings. The external rotor, which has a U-shaped cross section, wraps the three sides of the inner stator, while the rotor teeth are located on each side. Due to this unique mechanical configuration of triple airgap fields, the torque density is substantially boosted, since the torque is proportional to the airgap surface area for given electrical and magnetic loadings [3].

\section{Derivation of 3D field PMFS machine}

The 3D field PMFS machine can be derived in two ways.

In the first way, it can be figured out from a tubular linear PMFS machine, as illustrated in Fig. 3. The tubular PMFS linear machine was initially developed from a PMFS rotary machine, as shown in Fig. 3a. If the axis of the linear machine is bended, Fig. 3b, a 3D field tubular PMFS machine is obtained. It turns a linear machine back to rotary machine, which is already different from the initial rotary configuration which was proposed in [1]. Additionally, the inner side of the rotor is removed such that the stator can be fixed on a shaft. Thus, the proposed 3D field PMFS machine is achieved. As a result, most merits of the tubular linear PMFS machine are inherited in the $3 \mathrm{D}$ field rotary PMFS machine.

In the second way, the 3D field PMFS machine can be also obtained by combining an external-rotor rotary PMFS machine and a rotor-stator-rotor axial-flux rotary PMFS machine, as illustrated in Fig.4. Clearly, the 3D field PMFS machine combines the synergy of both external-rotor radialflux and dual-rotor axial-flux topologies.

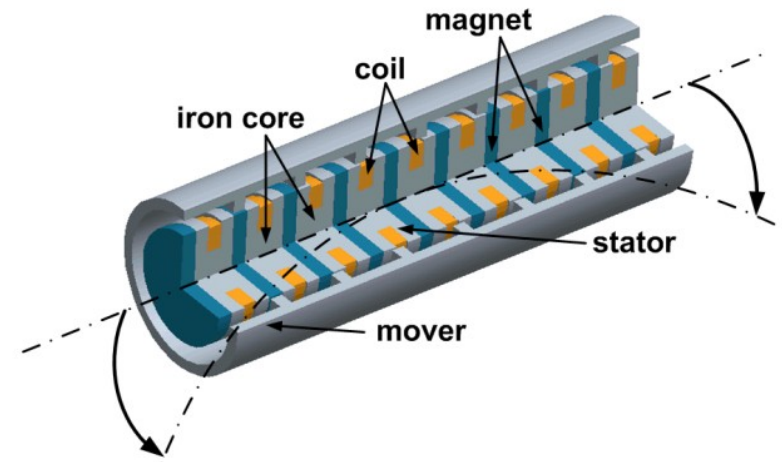

(a)

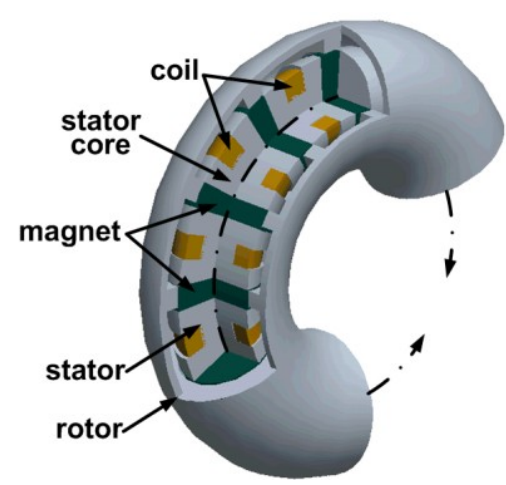

(b)

Fig. 3. Development of 3D field PMFS machine from tubular linear PMFS machine, (a) tubular linear PMFS machine, and (b) tubular linear PMFS machine being bended to original model of 3D field PMFS machine.

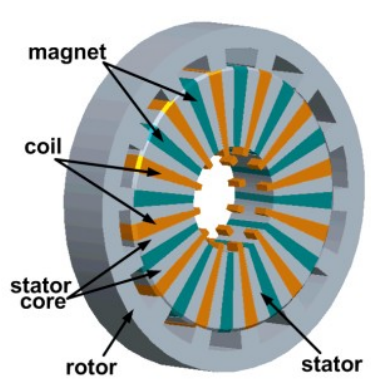

(a)

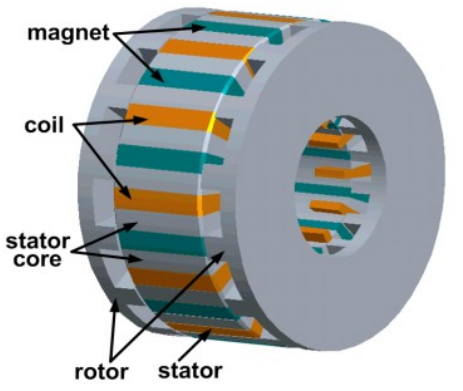

(b)
Fig. 4. Development of 3D field PMFS machine from external-rotor PMFS machine and rotor-stator-rotor axial-flux PMFS machine, (a) external-rotor PMFS machine, and (b) rotor-stator-rotor axial-flux PMFS machine.

\section{Winding structure consideration}

Toroidal coil is a common choice in the $3 \mathrm{D}$ field machines, where only one coil is located in each slot, as shown in Fig. $5 \mathrm{a}$, and it is easy for assembling. Another option is so called 
saddle coil, where two coils are set in a slot, as shown in Fig. $5 \mathrm{~b}$, which is more or less similar to the conventional PMFS machines. Note, in Fig. 5, the stator cores and magnets are set almost transparent, so that the coils are emphasized. Both coils have short end-windings since the inner diameter of the stator is small.

Refer to the following equation:

$$
P_{e} \propto v_{0} \cdot J_{0} \cdot S_{S}
$$

where $P_{e}$ is the electromagnetic power, $v_{0}$ is the rms value of the back-EMF in a single turn coil, $J_{0}$ is the current density, and $S_{S}$ is the slot area. Magnetic-circuit analysis shows that $v_{0}$ of the saddle coil is twice that of the toroidal coil, whilst $S_{S}$ of the saddle coil is a half of that of the toroidal coil. Therefore, the electric-output of both coil structures is almost the same.

A further consideration is that, the armature reaction field of saddle coil is essentially perpendicular to the axis of magnetization, hence, risk of irreversibly demagnetizing the magnets is low [4]. This allows high peak electric loading, and a high peak power density and peak torque capability. In contrast, the armature reaction field of toroidal coil is in the same direction with magnets and could cause higher risk of demagnetizing. Thus, saddle coil is preferred in the $3 \mathrm{D}$ field PMFS machine.

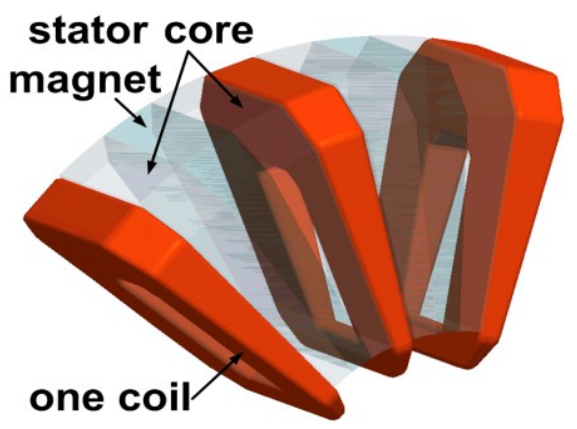

(a)

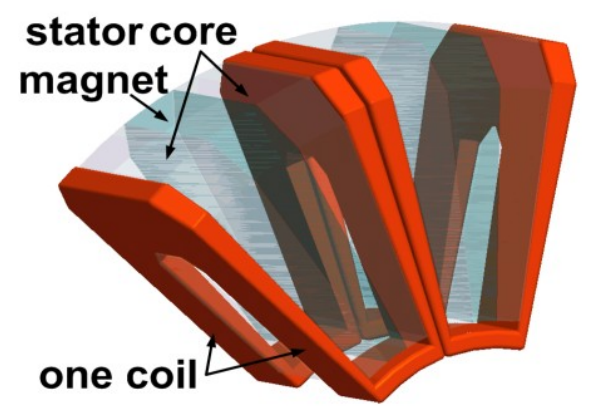

(b)

Fig. 5. Winding structures of 3D field PMFS machine, (a) toroidal coil, and (b) saddle coil.

\section{Simulation results}

3-dimensional finite element method (FEM) is employed to analyze the proposed machine. Fig. 6 shows the phase back-EMF waveforms of a 3D field PMFS machine, and also that of a 2D field external rotor PMFS machine (see Fig. 4a) with the same external diameter and stator axial length at the same speed. Note, the 2D machine is analyzed with 2dimensional FEM. As is evident, although the 3D field PMFS machine does not use any additional magnets, it has a higher back-EMF than the 2D field machine, resulting in a higher power output.

Furthermore, the back-EMF waveforms are sinusoidal, hence, the machines can run as either a brushless dc (BLDC) or a brushless ac (BLAC, also called permanent magnet synchronous motor (PMSM)) motor, with square-wave drive or sine-wave drive, respectively [5].

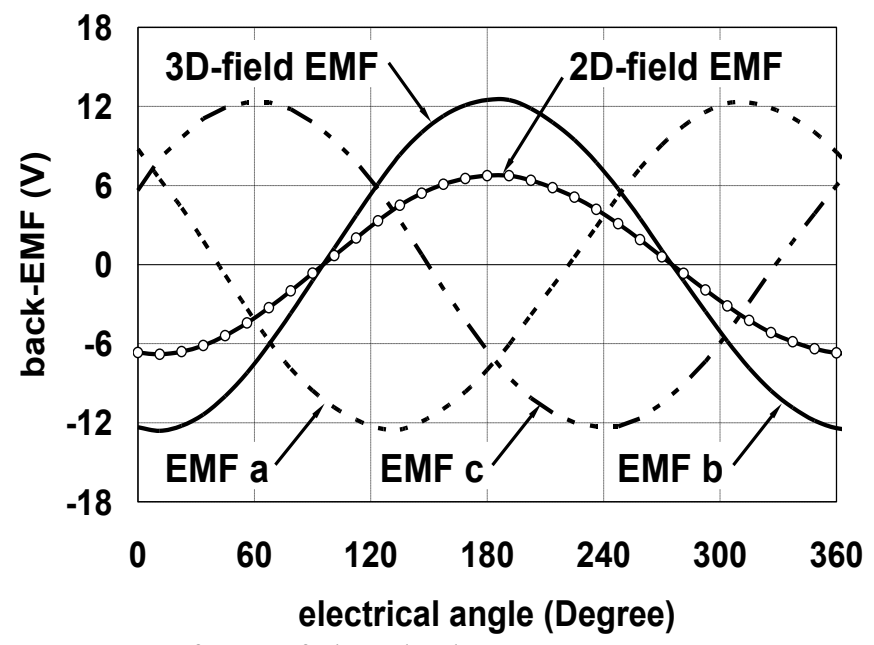

Fig. 6. Waveforms of phase back-EMF.

\section{Conclusion}

A novel 3D field PM flux-switching machine, which combines the merits of the tubular PMFS machines, externalrotor PMFS machines and dual-rotor axial-flux PMFS machines, is proposed and preliminarily investigated in this paper. Its configuration is derived, and its phase back-EMF is simulated with FEM, being superior to that of a conventional 2D field PM flux-switching machine.

The proposed 3D machine offers a higher power and torque density, and exhibits more efficient use of magnets due to the particular structure of large airgap surface area. It also exhibits a high peak torque capability due to little demagnetization effect of armature reaction on the magnets. 
All these positive features make the 3D field PMFS machine feasible for wide range applications.

\section{Acknowledgements}

This work was supported by National Natural Science Foundation of China (NSFC, 50677061) and Qianjiang Professionals Program of Zhejiang Province (2006R10014).

\section{References}

[1] S. E. Rauch, and L. J. Johnson: 'Design Principles of the Flux Switch Alternator', AIEE Transactions, 1955, 74111, Page(s):1261-1268

[2] C. F. Wang, J. X. Shen, L. L. Wang and K. Wang: 'A Novel Permanent Magnet Flux-Switching Linear Motor', the 4th IET International Conference on Power Electronics, Machines and Drives (PEMD), 2008, Page(s):116-119

[3] R. Qu, and T. A. Lipo: 'Dual-rotor, Radial-flux, Toroidally wound, Permanent-magnet Machines', IEEE Transactions on Industry Applications, Volume 39, No.6, Nov/Dec 2003, Page(s):1665-1673

[4] J. Wang, W. Wang, R, Clark, K. Atallah, and D. Howe: 'A Tubular Flux-switching Permanent Magnet Machine', Journal of Applied Physics, 2008, 103, 07F105-1 3

[5] W. Z. Fei, and J. X. Shen: 'Novel Permanent Magnet Switching Flux Motors', Universities Power Engineering Conference, 2006. UPEC '06. Proceedings of the 41st International, Volume 2, 6-8 Sept. 2006, Page(s):729-733

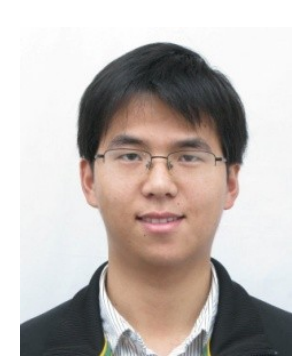

Can-Fei Wang received the B.E. degree and the Ph.D. degree from Zhejiang University, Hangzhou, China, in 2007 and 2012, respectively, both in electrical engineering. He is now with Hangzhou Municipal Electric Power Bureau as an electrical engineer since 2012. He has published nearly 30 technical papers and holds 25 patents. His main research interest is machine design and control.

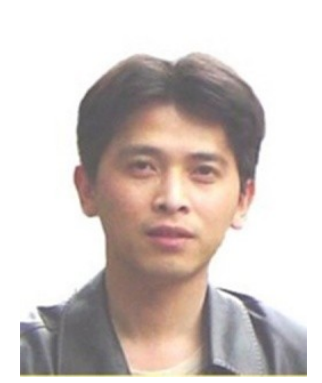

Jian-Xin Shen received the B.Eng. and M.Sc. degrees from Xi'an Jiaotong University, Xi'an, China, in 1991 and 1994, respectively, and the Ph.D. degree from Zhejiang University, Hangzhou, China, in 1997, all in electrical engineering. He was with Nanyang Technological University, Singapore (1997-1999), the University of Sheffield, Sheffield, U.K. (1999-2002), and IMRA Europe SAS, U.K. Research Centre, Brighton, U.K.
(2002-2004). Since 2004, he has been a professor of electrical engineering at Zhejiang University. He has published more than 130 technical papers and holds more than 30 patents. His main research interests include topologies, control and applications of permanent-magnet machine drives. For more information, see http://mypage.zju.edu.cn/en/jxs. 